Research Article

\title{
Design Method and Verification of Electroosmosis-Vacuum Preloading Method for Sand-Interlayered Soft Foundation
}

\author{
Yunliang Cui $\mathbb{D},{ }^{1}$ Jianbo Tu $\mathbb{D}^{2},{ }^{2}$ Xinquan Wang $\mathbb{D},{ }^{1}$ Hongguo Diao $\mathbb{D},{ }^{1}$ and Qianru Ge ${ }^{2}$ \\ ${ }^{1}$ Department of Civil Engineering, Zhejiang University City College, Hangzhou 310015, China \\ ${ }^{2}$ Zhejiang Provincial Institute of Communications Planning Design and Research. Co., Ltd., Hangzhou 310015, China
}

Correspondence should be addressed to Yunliang Cui; cuiyl@zucc.edu.cn

Received 3 September 2019; Revised 9 April 2020; Accepted 26 May 2020; Published 13 June 2020

Academic Editor: Melina Bosco

Copyright ( 2020 Yunliang Cui et al. This is an open access article distributed under the Creative Commons Attribution License, which permits unrestricted use, distribution, and reproduction in any medium, provided the original work is properly cited.

The design method of electroosmosis-vacuum preloading for soft foundation treatment is not systematic and complete, thereby restricting the application of the technology in engineering. A design method for the electroosmosis-vacuum preloading treatment of sand-interlayered soft foundation is therefore presented. A compressible electrical prefabricated vertical drain is developed, and a vacuum sealing and draining system is designed for the application of the electroosmosis-vacuum preloading in sandinterlayered soft foundation. Calculation formulas of site resistance considering the interlayer and interface resistivity of the electrode are established to design the power supply and electrical circuit. A simple numerical simulation method is proposed to predict the ground settlement treated by electroosmosis-vacuum preloading. A field test of electroosmosis-vacuum preloading is designed using the suggested method, and comparison tests between the electroosmosis-vacuum preloading and the vacuum preloading are performed to verify the proposed technique. The test results show that the proposed design method is reasonable for the design of electroosmosis-vacuum preloading in engineering.

\section{Introduction}

Many geotechnical researchers have studied electroosmosis technology since it was introduced to soft ground improvement engineering by Casagrande [1]. A large number of laboratory tests have been conducted to study the characteristics and related laws of soft soil consolidation by electroosmosis and the effectiveness of electroosmosis for soft ground improvement [2-4]. The electroosmosis method has also been implemented in many field tests [5-7]. Test results have shown that consolidation by electroosmosis only is relatively less efficient, and the combined application of the electroosmosis method and other foundation treatment methods can achieve a better result. The combined applications of electroosmosis and vacuum preloading $[8,9]$, electroosmosis and dynamic consolidation [10], electroosmosis and pneumatic fracturing [11], and electroosmosis and chemical [12], among others, have been verified in laboratory or field tests. Some theories have also been established for the design of electroosmosis for soft soil foundation. Zhuang and Wang [12] proposed the interface voltage drop hypothesis, based on which a simple interface resistance expression was given, to calculate the current and energy consumption of consolidation by electroosmosis. Wang et al. [13] proposed the design, calculation steps, and estimation methods of relevant parameters for the treatment of wet soil by electroosmosis. Zhuang [14] gave the main procedures and design contents of the electroosmotic drainage consolidation design and developed a determination method of water discharge, electroosmosis system, treatment time, etc. The above studies provide a good reference for calculating electroosmotic current and energy consumption, but they did not consider the influence of sand layer in ground. To simulate electroosmosis consolidation with a numerical method, Yuan and Hicks $[15,16]$ proposed a numerical model for the numerical analysis of electroosmosis consolidation and verified it with a case study. Chang and Sheen [17] used the excess pore water pressure of the three-dimensional consolidation behavior to deduce the three-dimensional electroosmotic equation under solar 
energy electroosmosis. $\mathrm{Hu}$ and $\mathrm{Wu}$ [18] proposed a mathematical model of electroosmotic consolidation for soft ground improvement based on the finite element method. The above method can be used to simulate the electroosmotic consolidation of simple cases, but its use for the modeling of complex projects is challenging and not accessible for engineers to master.

In summary, the above design theories are not complete and sufficient for the engineering design of electroosmosisvacuum preloading and the prediction of foundation settlement. Although there is research on the design method of electroosmosis, the design of the combined method of vacuum preloading and electroosmosis has not been fully studied. No systematic and complete design method can be used to design the electroosmosis-vacuum method. Notably, the deep soft soil foundation in coastal areas often has a certain thickness of sand interlayers. These interlayers are rich in water and have a significant permeability coefficient. This will quickly lead to electrode corrosion, line overload from the excessive current, and air leak of the vacuum sealing system in the electroosmosis-vacuum preloading treatment. Proper and accurate designs are needed for the electrode, vacuum sealing system, and circuit system. In this study, a relatively complete design method for electroosmosis-vacuum preloading was developed and verified by a field test.

\section{Design Methods}

2.1. Electrode Design. The electrode in the soft soil foundation improvement system in the electroosmosis-vacuum preloading method should be electrically conductive and drainable. The electrode should be flexible or compressible so that it does not pierce the vacuum geomembrane covering on the foundation surface during the settlement of the foundation. For a soft soil foundation with a sand layer, the water flow in the sand layer may easily lead to a short circuit, resulting in an excessive current in the circuit of the electroosmosis system; thus, the electrode should be insulated in the sand layer. The electrical prefabricated vertical drain (ePVD) is proposed in this work to meet the requirements above. The ePVD is made of a galvanized steel pipe with holes drilled all over. The pipe is wrapped in a geotextile filter cloth. A spring hose and a copper core wire are connected at the top. The copper core wire is connected to the galvanized steel pipe with a steel ring, and the joint of the cable and the steel pipe is wrapped in rubber tape for corrosion protection. A diagram of the proposed ePVD can be seen in Figure 1. The spring hose can be compressed during the foundation settlement to avoid piercing the vacuum geomembrane, and the spring hose can be directly connected to the horizontal drainage pipe to improve the vacuum transfer effect. In practice, a hole is drilled into the foundation with a highpressure water gun, and the ePVD is inserted into the hole. In this manner, the geotextile filter on the ePVD can remain in place/intact during construction. For a soft soil foundation with a sand layer, the ePVD is enwound with a rubber tape on the galvanized steel pipe in the sand layer so that this

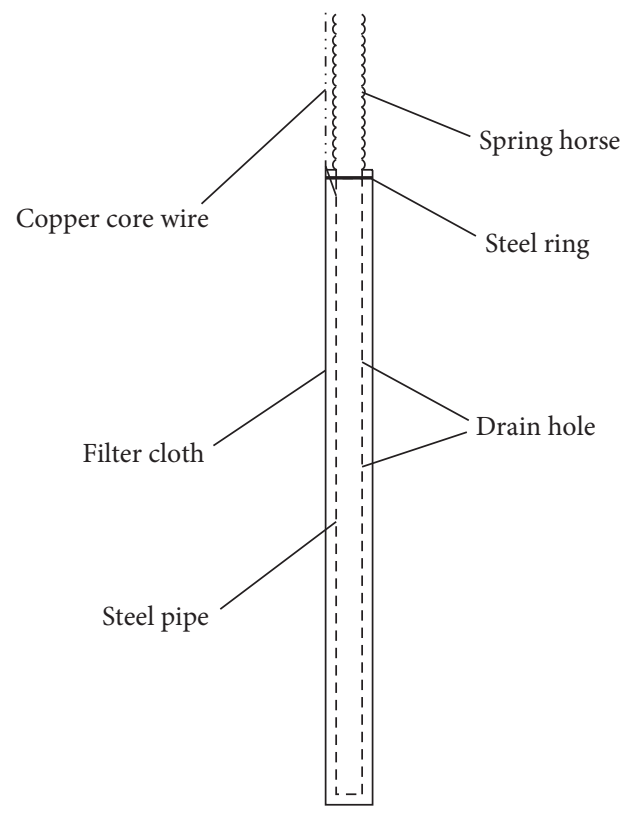

Figure 1: Diagram of the proposed ePVD.

part of the steel pipe is insulated from the surrounding aquifer.

In electroosmosis consolidation engineering, the spacing of the drainage electrodes has a great influence on the electroosmotic effect. At the same voltage, the smaller the electrode spacing, the larger the voltage gradient applied on the soil between the electrodes and the more obvious the electroosmotic effect. Because an excessively small electrode spacing will result in a high electrode material cost, the electrode spacing in electroosmosis engineering can refer to the electrical prefabricated vertical drain (PVD) spacing in the conventional vacuum preloading. The spacing is usually $1.0-1.5 \mathrm{~m}$, and the electrode is always arranged in a square or a quincunx. In soft ground improvement by the electroosmosis-vacuum preloading method, the electrode spacing can be appropriately increased to reduce the material cost, and the ePVD can be alternatively arranged with the conventional PVD. That is, the drainage electrode spacing is twice the PVD spacing; the drainage electrode and the PVD complement each other. The length of the electrode is determined according to the depth of the soft soil layer to be treated. For deeper soft soil layers, a short electrode and a long PVD can be combined. However, the length of the electrode should meet the treatment depth of the soft soil layer.

2.2. Power Supply and Circuit Design. DC power supply is the main equipment for foundation improvement engineering by the electroosmosis-vacuum preloading method. The power used in construction sites is usually $380 \mathrm{~V}$ threephase AC, which needs to be converted to DC by a DC power supply. The commonly used DC power supplies are mainly classified as unidirectional pulse or unidirectional constant DC power supplies. The current waveform output by the former is a high-frequency unidirectional square wave, and 
the current waveform output by the latter is a unidirectional constant direct current. According to an experimental study of the authors, pulse DC power supplies have high electroosmotic efficiency and are recommended over constant DC power supplies. The drainage electrodes inserted into the foundation are converged to the lead wire through branch wires and connected to the anode and the cathode of the DC power supply. The copper core wire or aluminum core cable can be optional for the circuit. Compared with copper core wires, aluminum core cables have poorer current-carrying capacity. Nevertheless, they are easy to heat and cheaper than copper core wires. In cases with low current, aluminum core cables can be used. In actual engineering, due to the high water content and low resistance of soil, there is a considerable demand for the current-carrying capacity of such wires and power from DC power supplies, which are also the limiting factors for electroosmotic treatment. Therefore, it is important to calculate the wire current and the power of the power supply. In the engineering design, the branch wire's current should be calculated according to the number of electrodes connected in series with each branch wire and then summarized to obtain the lead wire's current, thus separately determining the sectional area of the branch wire and that of the lead wire. Finally, the power required is calculated according to the lead wire's current and the design voltage. The higher the power, the heavier the power supply and the higher the price. In engineering, the large-area site should be divided into small-area electroosmotic blocks, each of which is controlled by a DC power supply.

The power of the power supply can be obtained by $P=U I$, in which $U$ is the output voltage of the power supply. Wu et al. [19] used a voltage of $40 \mathrm{~V}$ in their study, and Wang et al. [13] used an average voltage of $40 \mathrm{~V}$. The voltages used in Bjerrum et al. [5] and Lo et al. [6] were less than $70 \mathrm{~V}$ and $120 \mathrm{~V}$, respectively. The higher the voltage, the better the consolidation that can be achieved but the higher the cost. A voltage of $36 \mathrm{~V}$ was used in the present study for safe construction. $I$ is the total output current of the power supply, and the current is the sum of the current $I^{\prime}$ of each anode (or cathode) branch wire. The current of each anode branch wire is $I^{\prime}=U / \Sigma R^{\prime}$, where $\Sigma R^{\prime}$ is the total resistance of the area controlled by each anode branch wire. The electroosmotic circuit system is shown in Figure 2.

The total resistance $\Sigma R^{\prime}$ of the area controlled by each anode branch wire can be described by the apparent resistance of each anode-cathode pair. Each such pair and the soil between them are divided into a soil strip, as shown in Figure 2. The apparent resistance $R_{a}$ of the anode-cathode pair can be expressed by the following:

$$
R_{a}=R_{w}+R_{e}+R_{i}+R_{s},
$$

where $R_{w}$ is the resistance generated at the wire and the wire connection, $R_{e}$ is the resistance of the material of the drainage electrode, $R_{i}$ is the interface resistance of the electrodes and the surrounding soil, and $R_{s}$ is the resistance of the soil between the anode and the cathode. $R_{w}=0$ is assumed in the engineering cost estimate. When a metal electrode is used, $R_{e}=0$ can be assumed. Zhuang and Wang [12] gave formulas for calculating the interface resistance $R_{i}$

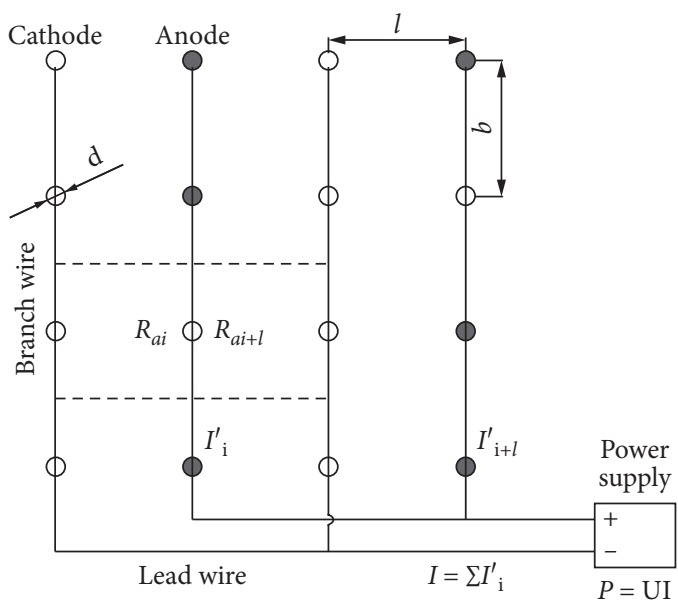

FIgURE 2: Schematic view of electroosmotic circuit.

and soil resistance $R_{s}$. The expressions of $R_{i}$ and $R_{s}$ proposed by Zhuang and Wang [12] can be rewritten as follows to consider the influence of the sand layer in the ground:

$$
\begin{aligned}
& R_{i}=\left(\frac{1}{d \sum h_{i}}-\frac{1}{b \sum h_{i}}\right) k_{j}, \\
& R_{s}=\frac{\rho_{s} l}{\sum h_{i} b},
\end{aligned}
$$

where $k_{j}$ is the interface resistivity $\left(\Omega \cdot \mathrm{m}^{-2}\right)$; $d$ is the anode or cathode diameter, $m$; and $h_{i}$ is the thickness of the soil layer $i$ in the electrode treatment range, $m$. The sand and soil layer thicknesses at the electrode top's spring hose are excluded for the case of using the ePVD to treat a foundation with a sand layer; $b$ is the anode spacing or cathode spacing, $m$. $\rho_{s}$ is the average resistivity of the soil between the anode and the cathode. The resistivity of each soil layer is weighted and averaged according to the thickness of the soil layer. The resistivities of the sand and soil layers at the electrode top's spring hose section are excluded for the case of using the ePVD to treat a foundation with a sand layer; $l$ is the distance between the anode and the cathode, $m$.

The apparent resistance of each anode-cathode pair connected to a branch wire is in a parallel connection. Therefore, the total resistance of the area controlled by each branch wire is $\Sigma R^{\prime}=R_{a} / n$, where $n$ is the number of anode-cathode pairs. Since one anode branch wire and two adjacent cathode branch wires form a loop, $n$ is twice the number of anodes connected to one branch wire. The current of each branch wire can be obtained by $I^{\prime}=U / \Sigma R^{\prime}$. According to the calculated current, the appropriate branch wire type can be selected according to the current-carrying capacity of the wire's sectional area. The total current of each power supply is $I=\Sigma I$ '. The sectional area of the lead wire can be determined based on the total current to select the appropriate lead wire type.

2.3. Vacuum Seal and Drainage System Design. For the application of the electroosmosis-vacuum preloading method for sand-interlayered soft foundation, a vacuum seal and drainage system are proposed, as seen in Figure 3. For 


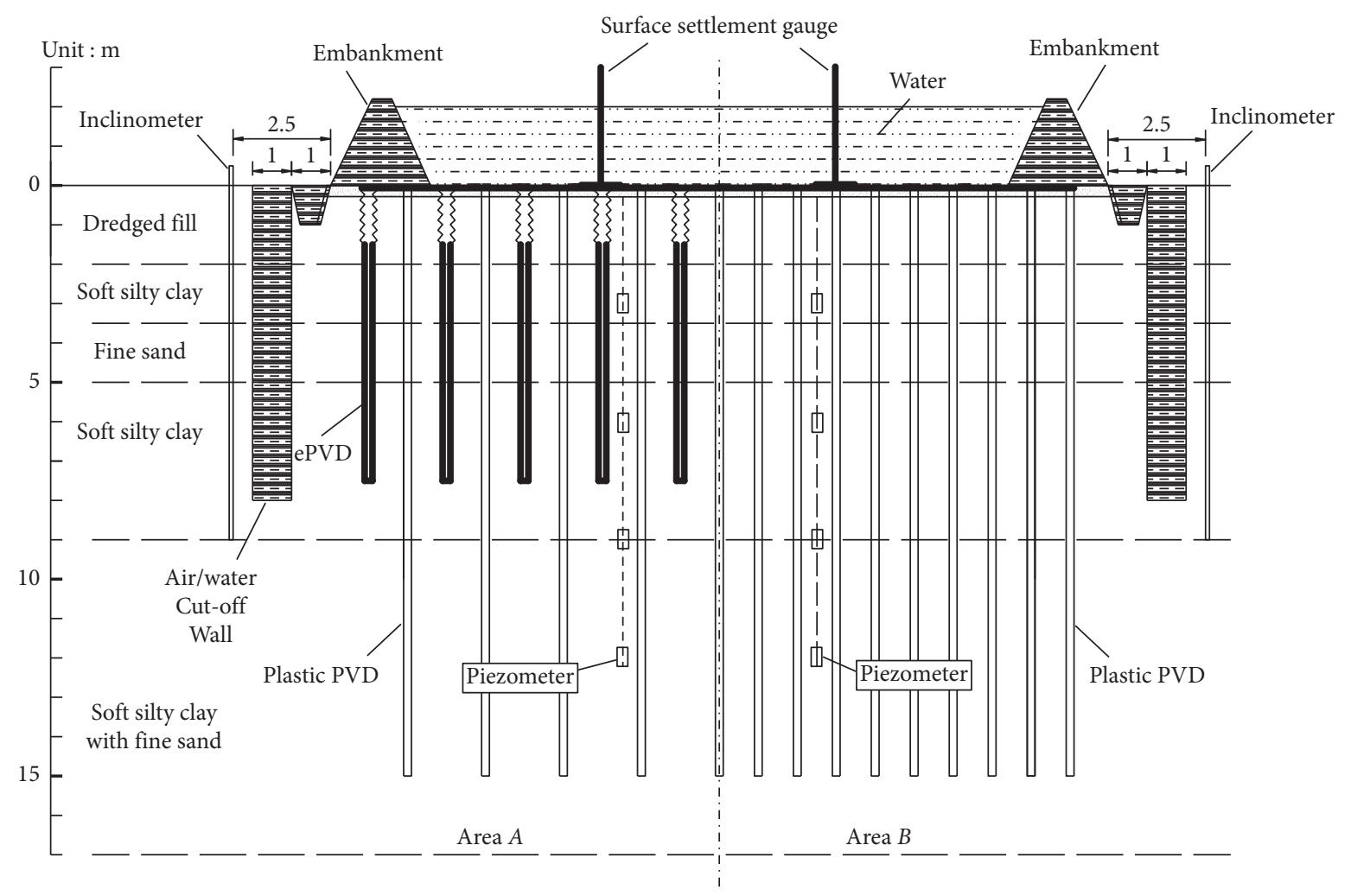

FIgURE 3: Vacuum seal and drainage system.

foundation with sand layers, air leakage can easily occur at the site during the vacuuming process, and the vacuum degree cannot meet the design requirements. Therefore, it is necessary to provide a sealing wall around the site to block the permeable layer. The mud mixing wall can be used as the sealing wall, and mud made of clay is poured into the foundation through a cement-mixing pile machine to form a clay sealing wall. The clay in the mud adopted by the clay sealing wall should be not less than $20 \%$, the clay grain content of the clay should be more than $20 \%$, the mud density should be $1.2-1.3$, and the permeability coefficient should be $k<1 \times 10^{-7} \mathrm{~m} / \mathrm{s}$. The clay sealing wall, usually 0.7-1.2 $\mathrm{m}$ wide, should be deeper than the sand layer.

For the deeper sand layer burial in this case, the mud mixing sealing wall could produce a good effect but would be easily ineffective under the vacuum pressure. A self-setting mortar wall is thus recommended for use as the sealing wall. For the geology of silty soft clay foundation with sand layers, the suggested mix proportion of the self-setting mortar according to the field test was as follows: cement (PO42.5): calcium bentonite: JM-VII retarder: sodium carbonate: water $=280: 62.5: 1.12: 5: 1000$. The thickness of the selfsetting mortar wall was $0.6-0.8 \mathrm{~m}$. According to the experiment, the permeability coefficient of the self-setting mortar wall was smaller than $1 \times 10^{-8} \mathrm{~m} / \mathrm{s}$, and the 28 -day unconfined compressive strength was more than $300 \mathrm{kPa}$.

In the site enclosed by the sealing wall, the drainage was carried out by the vacuum drainage system. The drainage electrode was used as a vertical drainage channel and directly connected to the horizontal drainage branch pipe laid on the surface of the site. The horizontal drainage branch pipes were converged to the horizontal drainage main pipe, which was connected to the vacuum pump. The site was covered with the vacuum geomembrane, which was buried in the clay along the periphery of the site to form a closed space for the site under treatment. After the geotextile was laid on the vacuum geomembrane, a cofferdam was built around the site and then injected with water for loading.

2.4. Settlement Prediction. Accurate prediction of foundation settlement is important for the design of soft soil foundation treatment. Some scholars have established the electroosmosis-vacuum preloading consolidation equation to calculate the settlement, but this requires compiling a finite element program, which is difficult for ordinary engineering technicians. To simplify the prediction of the settlement of soft soil foundation treated by the electroosmosis-vacuum preloading method, we propose a simple method of simulating electroosmosis consolidation with the finite element method, which is easy to master. The water flow caused by electroosmosis in the unit soil is assumed to be equal to that caused by the negative pressure. Under the same seepage flow, it can be deduced that the amount of negative pressure applied can make it equivalent to the drainage effect of the unit soil under a certain voltage. Although electroosmotic consolidation and negative pressure consolidation have different consolidation mechanisms, the consolidation settlement is most important for soft ground improvement engineering. Therefore, using negative 
pressure consolidation to approximately simulate the electroosmotic consolidation may satisfy the engineering needs under the same discharge of the unit soil.

According to Mitchell [20], the excess pore pressure at the cathode induced by electroosmosis can be determined by the following:

$$
u=-\left\{\frac{k_{e}}{k_{h}}\right\} \gamma_{w} \phi
$$

where $k_{e}$ is the electroosmosis coefficient, $k_{h}$ is the horizontal osmotic coefficient, and $\phi$ is the electrical potential at the cathode.

The unit seepage flow generated by the potential $\phi$ is equal to that generated by the negative excess pore pressure $u=-\left(k_{e} \gamma_{w} \phi / k_{h}\right)$. In the finite element simulation of electroosmosis consolidation, we propose that the negative excess pore pressure drainage method be used to approximately simulate the electroosmotic drainage. In the proposed method, the anode is set to an excess pore pressure boundary, and the excess pore pressure can be calculated by formula (4). During electroosmosis, water flows from the anode to the cathode and then is discharged from the cathode. The excess pore pressure at the cathode is kept at 0 , where no water is discharged at the anode and the pore water at the anode is discharged to the cathode. Then, a negative excess pore pressure is formed gradually at the anode, and the soil at the anode is first consolidated, resulting in a more significant settlement compared with that of the soil at the cathode. This is consistent with the law of consolidation settlement of the soil in the actual electroosmosis process. However, in the finite element simulation of electroosmosis using the proposed simplified method, the negative excess pore pressure applied at the anode will generate seepage from the cathode to the anode, which is inconsistent with the actual electroosmotic seepage direction; hence, this method is merely a simplified approximation method. Nevertheless, while ensuring equal displacement of the soil, this method can reflect the law that the soil at the anode is consolidated and settled earlier than that at the cathode. In soft ground improvement, settlement and displacement are the most crucial factors. The direction of seepage is not as important. Therefore, this method can be applied in soft soil foundation improvement engineering.

Although this method cannot reflect the mechanism of electroosmosis consolidation in essence, it can predict the settlement of the soil and be used for the settlement prediction of soft soil foundation treated by electroosmosisvacuum preloading. Accurately predicting the foundation settlement by the finite element simulation can help design the treatment process reasonably.

\section{Verification of the Design Methods}

3.1. Overview of the Test Area. The test was conducted on a dredged fill site. The dredged fill was consolidated by vacuum preloading. Roads needed to be built on the site, but the bearing capacity of the site could not meet the design requirements, so further treatment was needed. The upper layer of the site was the dredged fill consolidated by vacuum preloading. The lower layer of the soil was mainly mucky silty clay, between which a sand interlayer about $1.5 \mathrm{~m}$ thick was sandwiched. The groundwater level was $0.5 \mathrm{~m}$ below the ground. A static bearing test showed that the average bearing capacity of the soft soil foundation was about $55 \mathrm{kPa}$. The soil parameters in the test area are shown in Table 1.

The total test area was $1200 \mathrm{~m}^{2}$, and it was divided into four small subareas each sized $20 \mathrm{~m} \times 15 \mathrm{~m}$. The four subareas were named $A 1, A 2, A 3$, and $B$ zones. The $A 1, A 2$, and $A 3$ zones were subjected to the electroosmosis-vacuum preloading test, and the $B$ zone to the conventional vacuum preloading test.

3.2. Design of Field Test. EPVDs (outer diameter: $0.024 \mathrm{~m}$; inner diameter: $0.02 \mathrm{~m}$ ) were inserted in the ground up to a depth of $7.5 \mathrm{~m}$. The upper $1.5 \mathrm{~m}$ was a spring hose, and the lower $6 \mathrm{~m}$ depth acted as an electrode. There was a sand interlayer in the foundation, so the electrodes were insulated in the depth range of the sand interlayer. The electrode spacing was $2 \mathrm{~m}$, and the electrodes were arranged in a square. The PVDs were installed between the ePVDs to add more drainage channels, and the PVD spacing was $1 \mathrm{~m}$. The $\operatorname{PVD}(0.1 \mathrm{~m} \times 0.004 \mathrm{~m})$ was used in the conventional vacuum preloading test area. In this area, the PVD spacing was $1 \mathrm{~m}$. They were arranged in a square, and the depth of insertion into the foundation was $15 \mathrm{~m}$. Because the foundation had a sand interlayer ranging from $3.5 \mathrm{~m}$ to $5 \mathrm{~m}$ deep, a self-setting mortar wall measuring $1 \mathrm{~m}$ thick and $8 \mathrm{~m}$ deep was used to seal the site. The branch wires were arranged in the direction of the side of the test area with a length of $15 \mathrm{~m}$, including five anode branch wires and six cathode branch wires. Eight electrodes were connected in series on each branch wire. The arrangement of the branch wires, lead wires, and electrodes can be seen in Figure 3.

The proposed design method in this study was used to design the circuit, power supply, and settlement in the experiment. First, the soil resistivity of the site samples was determined by a Miller Soil Box. The average resistivity of the site was $\rho_{ \pm}=3 \Omega \cdot \mathrm{m}$. According to formula (3), the soil resistance between an anode-cathode pair can be calculated by $R_{s}=(3 \times 2 / 2 \times(5+1.5+2.5))=0.67 \Omega$.

To determine the interface resistivity $k_{j}$, we inserted two ePVDs into the foundation as the cathode and the anode with a spacing of $2 \mathrm{~m}$, and then, a $36 \mathrm{~V}$ DC supply was connected. The measured initial current was about $8.5 \mathrm{~A}$, and the resistance of the circuit was $4.24 \Omega$. Therefore, the interface resistivity was $k_{\mathrm{j}}=0.3897 \Omega \cdot \mathrm{m}^{2}$. According to formula (2), the interface resistance of an anode-cathode pair was $R_{i}=((1 /(0.024 \times 4.5))-(1 /(2 \times 4.5))) \times 0.3897=$ $3.57 \Omega$. Assuming that the resistance of the circuit and the metal electrode was negligible and the initial interface resistance of the cathode and the anode was the same, $R_{a}=$ $0+0+0.67+3.57 \times 2=7.81 \Omega \Omega$ was obtained according to formula (1). Thus, the total resistance of the area controlled by each branch wire was $\Sigma R^{\prime}=7.81 /(8 \times 2)=0.49 \Omega$. The adopted input voltage was $36 \mathrm{~V}$ for safe construction. The current of each anode branch wire was $I^{\prime}=36 /$ $0.49=73.8 \mathrm{~A}$, and five anode branch wires were arranged in each test area, so the total current of the lead wire was 
TABLE 1: Statistics of physical and mechanical characteristics of soil.

\begin{tabular}{|c|c|c|c|c|c|c|c|c|c|}
\hline Soil layer & $\begin{array}{c}\text { Thickness } \\
(h) \\
\mathrm{m}\end{array}$ & $\begin{array}{c}\text { Natural } \\
\text { density } \\
(\gamma) \\
\mathrm{kN} / \mathrm{m}^{3}\end{array}$ & $\begin{array}{c}\text { Moisture } \\
\text { content } \\
(W) \\
\%\end{array}$ & $\begin{array}{c}\text { Void } \\
\text { ratio } \\
(e)\end{array}$ & $\begin{array}{c}\text { Compression } \\
\text { modulus (Es) } \\
\mathrm{MPa}\end{array}$ & $\begin{array}{c}\text { Cohesion } \\
(C) \\
\mathrm{kPa}\end{array}$ & $\begin{array}{c}\text { Internal } \\
\text { friction } \\
\text { angle }(\Phi) \\
\text { o }\end{array}$ & $\begin{array}{c}\text { Horizontal } \\
\text { permeability } \\
\text { coefficient }\left(k_{\mathrm{h}}\right) \\
10^{-9} \mathrm{~m} / \mathrm{s}\end{array}$ & $\begin{array}{c}\text { Vertical } \\
\text { permeability } \\
\text { coefficient }\left(k_{\mathrm{v}}\right) \\
10^{-9} \mathrm{~m} / \mathrm{s}\end{array}$ \\
\hline $\begin{array}{l}\text { (1) Dredged } \\
\text { fill } \\
\text { (2) }-1\end{array}$ & 2.0 & 17.8 & 48.8 & 1.32 & 2.42 & 12.9 & 10.3 & 6.6 & 3.8 \\
\hline $\begin{array}{l}\text { Mucky silty } \\
\text { clay }\end{array}$ & 1.5 & 18.0 & 42.1 & 1.42 & 2.83 & 13.3 & 11.6 & 8.6 & 5.4 \\
\hline $\begin{array}{l}\text { (3) Sand } \\
\text { interlayer } \\
\text { (2) }-2\end{array}$ & 1.5 & 19.5 & 39.4 & 1.25 & 3.25 & 7.5 & 24.1 & 84.7 & 71.5 \\
\hline $\begin{array}{l}\text { Mucky silty } \\
\text { clay }\end{array}$ & 4.0 & 18.2 & 44.8 & 1.43 & 2.86 & 14.5 & 11.1 & 8.2 & 4.6 \\
\hline $\begin{array}{l}\text { (4) Silty } \\
\text { clay with } \\
\text { sand }\end{array}$ & 20.0 & 18.9 & 43.4 & 1.34 & 2.94 & 9.5 & 12.7 & 9.8 & 4.5 \\
\hline
\end{tabular}

$I=73.8 \times 5=369$ A. With reference to the current-carrying capacity of aluminum core insulated wires and considering the safety factor, two aluminum core insulated wires with a nominal cross-section of $70 \mathrm{~mm}^{2}$ were combined as one lead wire with a current-carrying capacity of $420 \mathrm{~A}$. Aluminum core insulated wires with a nominal cross-section of $16 \mathrm{~mm}^{2}$ were used as the branch wire with a current-carrying capacity of $90 \mathrm{~A}$. The output power of the power supply could be calculated by $P=369 \times 36=13284 \mathrm{~W}$. Therefore, given a certain safety factor, we selected a high-frequency switching DC power supply with a stable voltage and a steady current output, with an output voltage of $40 \mathrm{~V}$, output current of $500 \mathrm{~A}$, and output power of $20000 \mathrm{~W}$. The input voltage was three-phase AC $380 \mathrm{~V}$, and the output was a high-stability $25 \mathrm{kHz}$ high-frequency wave.

3.3. Test Method. The $A 1, A 2$, and $A 3$ zones were powered by a DC power supply and received the vacuum electroosmosissurcharge preloading under the same voltage. The conventional vacuum-surcharge preloading test was performed in the $B$ zone. The $A$ and $B$ zones were covered with a complete vacuum geomembrane, and the vacuum degree under the geomembrane reached $85-90 \mathrm{kPa}$ in 10 days because of the vacuuming with the vacuum pump. A surcharge load of $20 \mathrm{kPa}$ was applied after 15 days by pouring water on the vacuum geomembrane. Then, the electroosmosis-vacuum and surcharge preloading kept acting for 30 days. The vacuum and surcharge loads are shown in Figure 4.

After 20 days of electroosmotic operation, current transition was performed every five days. That is, the anode was changed to be the cathode, and the cathode was changed to be the anode. Current transition could prevent the formation of large interface resistances at the anode, which reduce the efficiency of electroosmosis after long-term application.

\section{Field Test Results Analysis}

Three electroosmotic power supplies were set at $36 \mathrm{~V}$ constant voltage output mode to verify the rationality of the wire

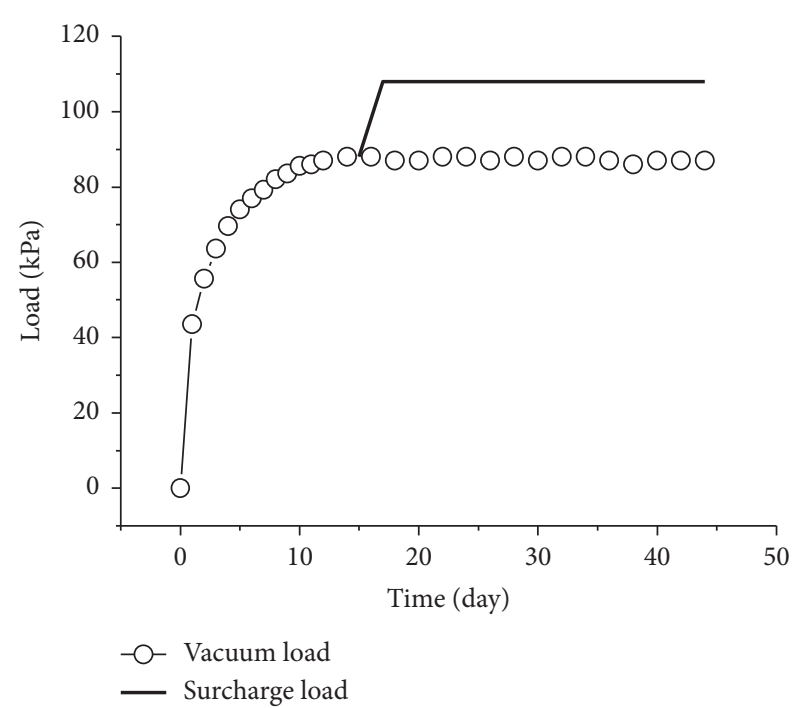

FIGURE 4: Vacuum degree under geomembrane and surcharge load.

and power supply selection. At the initial stage of electroosmosis, the lead wire currents monitored at the $A 1, A 2$, and A3 zones were about $390 \mathrm{~A}, 384 \mathrm{~A}$, and $380 \mathrm{~A}$, respectively. Therefore, the current-carrying capacity of the wire and the output power of the power supply selected could meet the requirements. Compared with the monitoring results, the calculated results had some errors, but the calculation accuracy could meet engineering needs.

The voltage difference was measured every $0.1 \mathrm{~m}$ along the direction to the anode with the cathode as the center, and the normalized voltage distribution is shown in Figure 5. The voltage distributions reported in references [6, 7] were compared in Figure 5 with that in this study. The figure shows that the voltage loss at the cathode and the anode accounted for a large proportion of the total voltage. According to this study, $14 \%-17 \%$ of the voltage loss was at the cathode; $33 \%-49 \%$ was at the anode; and $37 \%-50 \%$ of the voltage remained in the soil. The voltage consumption at the cathode and the anode was mainly caused by the 


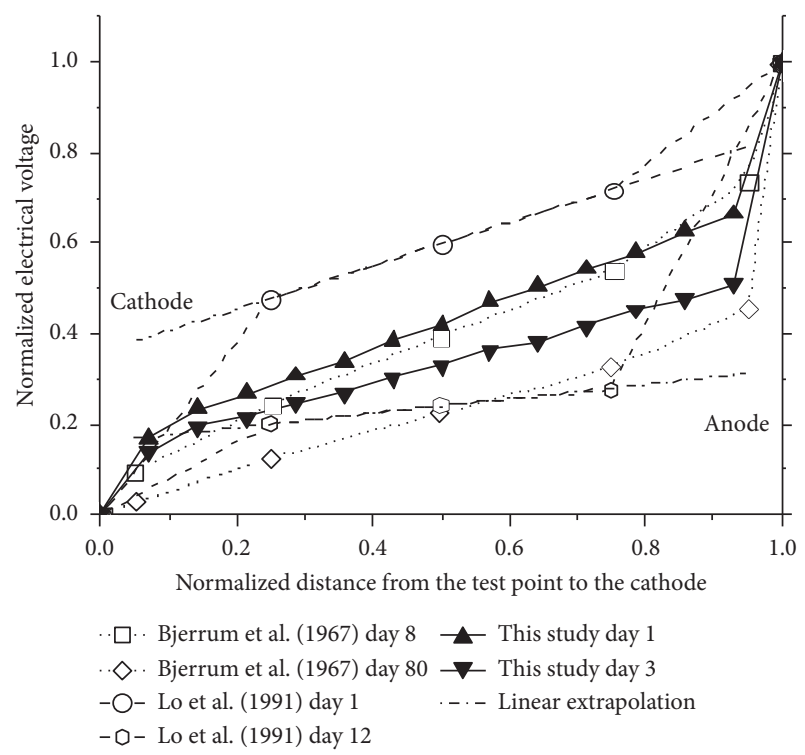

Figure 5: Distribution of voltage between anode and cathode.

interface resistance, so it was necessary to consider the interface resistance in calculating the overall resistance of the site in the electroosmosis design. Because the soil moisture contents around the cathode and the anode are different and the contact of the electrode with the soil changes rapidly after the electroosmosis begins, different interface resistivities should be adopted at the cathode and the anode. Moreover, interface resistivity varies greatly with soil layers; therefore, the interface resistance should be computed by using the average resistivity of the soil layer that is in contact with the electrode.

Settling plates were set in the test zones to monitor the surface settlement of the foundation. All settling plates were placed in the middle of the adjacent vertical drainage channels. The surface settlements of the sites are shown in Figure 6.

As shown in Figure 6, in stage 1 (before surcharge loading), the $A 1, A 2$, and $A 3$ zones were subjected to the combined action of vacuum preloading and electroosmosis, whereas the $B$ zone underwent only vacuum preloading. In the second stage, from the 15th day after the start of the test, the surcharge load was applied in all the zones. In Figure 6, $V$ stands for vacuum preloading, $E$ for electroosmosis, and $S$ for surcharge load. The morphology of the settlement curve in Figure 6 shows that the settlement increased sharply after the surcharge loading. A comparison of the settlements of the $A$ and $B$ zones reveals that the settlement of the electroosmosis-vacuum preloading test area was $20 \%$ higher than that of the vacuum-surcharge preloading test area. Therefore, the electroosmosis-vacuum preloading test designed by the proposed method can promote a faster and larger consolidation settlement of soft soil foundation with sand interlayers.

We used the finite element software ABAQUS to numerically simulate the electroosmosis-vacuum preloading test and verify the rationality of the proposed numerical simulation method. According to the proposed method,

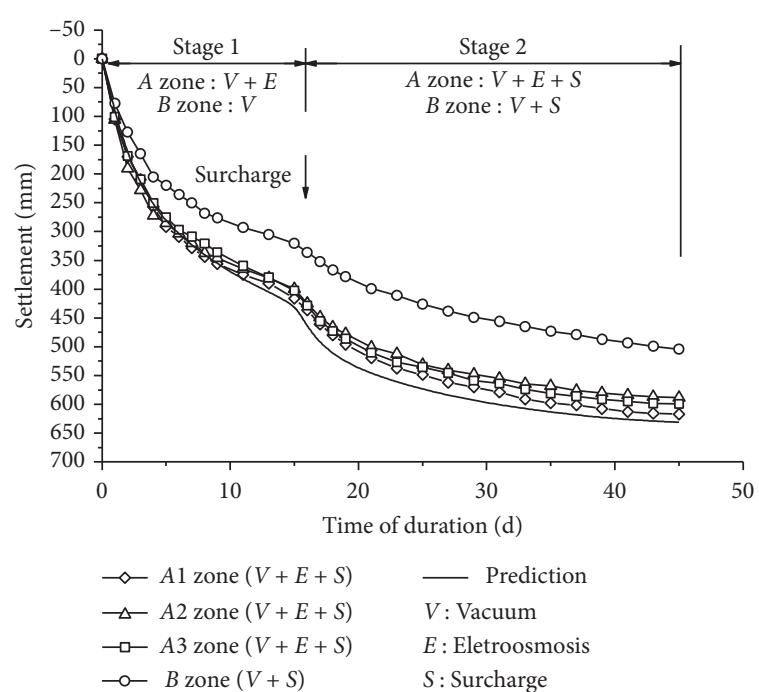

Figure 6: Surface settlements of test zones.

excess pore pressure was applied on the PVDs and ePVDs in the simulation. As shown in Table 1, the average horizontal osmotic coefficient of the soil within the effective electrode depth range was calculated as $k_{h}=8.2 \times 10^{-9} \mathrm{~m} / \mathrm{s}$. Mitchell [20] stated that the value of the electroosmotic coefficient $k_{e}$ should be between $1 \times 10^{-9}$ and $1 \times 10^{-8} \mathrm{~m}^{2} / \mathrm{V} / \mathrm{s}$. According to the common values in previous studies, the electroosmotic coefficient of the soil taken in the calculation was $k_{e}=2 \times 10^{-9} \mathrm{~m}^{2} / \mathrm{V} / \mathrm{s}$. In the field test, the power output voltage was $\phi=36 \mathrm{~V}$. The study result of the voltage distribution between the electrodes showed that only $37 \%-50 \%$ of the voltage remained in the soil, and the average value of $44 \%$ was used in the calculation. Thus, the actual applied voltage in the soil was $16 \mathrm{~V}$, and the excess pore water pressure applied to the vertical drainage body in the simulation was $-39 \mathrm{kPa}$, according to formula (4). The converted excess pore pressure and the actually applied vacuum degree were superposed and applied to the anode in the numerical simulation. A two-dimensional finite element model was established with ABAQUS for the electroosmosis-vacuum preloading test simulation, and the Mohr-Coulomb model was used for the soil constitutive model. The soil parameters are shown in Table 1. The settlement curve of the central point on the foundation surface in the electroosmosis-vacuum preloading area obtained by the numerical simulation settlement curve is shown in Figure 6 . The foundation settlement contour is shown in Figure 7. The average measured settlement of $\mathrm{A}$ zone at the end of stage 1 is $406.1 \mathrm{~mm}$, and the simulated settlement is $427.8 \mathrm{~mm}$. Compared with the measured data, the error of the simulation results is only $5.3 \%$. The average measured settlement of A zone at the end of stage 2 is $601.5 \mathrm{~mm}$, and the simulated settlement is $631.1 \mathrm{~mm}$. Compared with the measured data, the error of the simulation results at the end of stage 2 is only $4.9 \%$. The simulation errors of the two stages are acceptable in engineering. By comparing the simulation curve with the measured curves in Figure 6, it can be found that the finite element simulation curve agrees well 


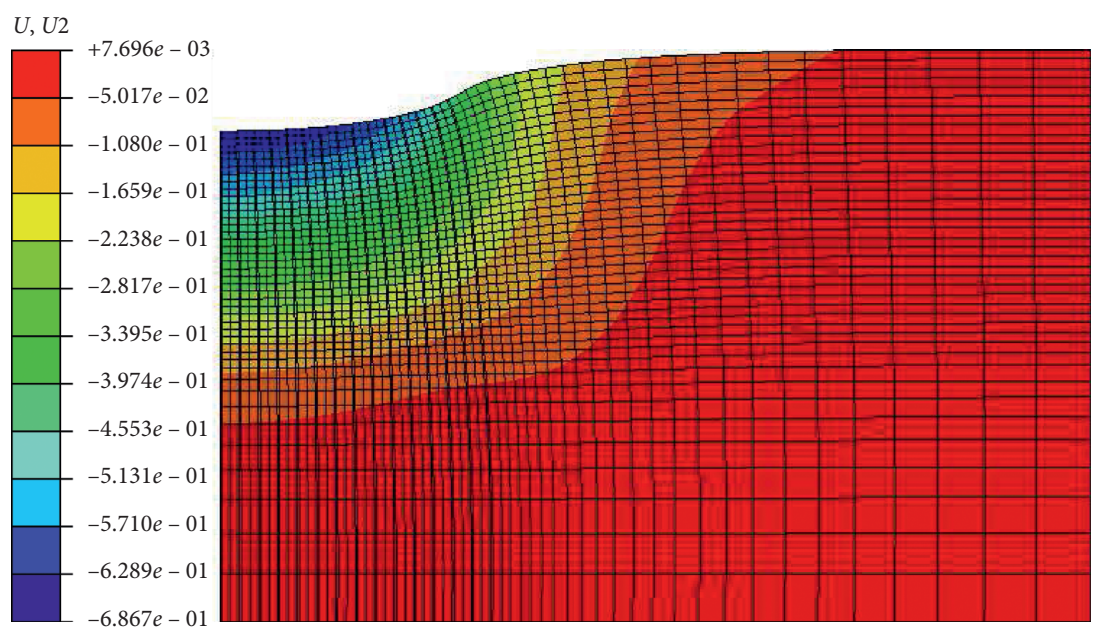

Figure 7: Settlement contour by finite element simulation.

with the settlement data of the electroosmosis-vacuum preloading test area. It indicates that the numerical simulation has a high precision. This proves that the proposed simulation method is feasible for predicting the foundation settlement of electroosmosis-vacuum preloading, and its calculation accuracy can meet engineering needs.

\section{Conclusions}

Aiming at the treatment design of soft soil foundation with sand interlayers by the electroosmosis-vacuum preloading method, a design method that includes the ePVD design, power supply and conducting circuit design, vacuum seal and drainage system design, and settlement prediction was developed and verified with a field test. The following results are concluded through the study:

(1) The developed compressible ePVD has the functions of both conductivity and drainage and can isolate the sand interlayer without puncturing the vacuum geomembrane. Therefore, it is suitable for the treatment of sand-interlayered soft soil foundation with the electroosmosis-vacuum preloading method.

(2) Reasonable circuit and supply power design is the key to electroosmosis treatment engineering. The influence of interface resistance and the sand interlayer should be considered to accurately calculate the site resistance. The proposed calculation method can be used to reasonably calculate the wire sectional area and the power of the power supply.

(3) The sealing effect of the site should be guaranteed for soft soil foundation with sand interlayers. A selfsetting mortar wall is recommended for vacuum sealing. The mixing ratio of the self-setting mortar obtained in this work can be used for soft soil foundation with sand interlayers.

(4) A simplified finite simulation method for electroosmosis consolidation is proposed. Under an equal seepage flow of the unit soil, the voltage can be converted into the excess pore pressure and applied to the drainage boundary. The simulation method can be used to predict the settlement of a site by electroosmosis-vacuum preloading.

\section{Notation}

PVD: Prefabricated vertical drain

$R_{s}$ : $\quad$ Resistance of the soil between electrodes

ePVD: Electrical PVD

$k_{j}$ : $\quad$ Interface resistivity

AC, Alternating current and direct current

DC:

$h_{i}$ : $\quad$ Soil thickness of the layer $i$ in the electrode treatment range

$P, U: \quad$ Output power and voltage

$B: \quad$ Anode spacing or cathode spacing

$I, I^{\prime}: \quad$ Total current and the current of each branch wire

$\rho_{s}$ : $\quad$ Average resistivity of the soil between the anode and the cathode

$\Sigma R^{\prime}$ : Total resistance of the area controlled by each branch wire

$l$ : $\quad$ Distance between the anode and the cathode

$R_{a}$ : $\quad$ Apparent resistance of a pair of electrodes

$k_{e}: \quad$ Electroosmosis coefficient

$R_{w}$ : Resistance generated at the wire and the wire connection

$k_{h}$ : Horizontal osmotic coefficient

$R_{e}: \quad$ Resistance of the material of the drainage electrode $\phi: \quad$ Electrical potential at the cathode

$R_{i}$ : $\quad$ Interface resistance between the electrode and the surrounding soil

$u$ : $\quad$ Excess pore pressure at the cathode.

\section{Data Availability}

The data used to support the findings of this study are available from the corresponding author upon request.

\section{Conflicts of Interest}

The authors declare no conflicts of interest. 


\section{Acknowledgments}

This work was financially supported by the Zhejiang Provincial Natural Science Foundation of China (Grant no. LGF20E080007), National Natural Science Foundation of China (Grant nos. 51508507 and 51808493), and Scientific Research Project of Zhejiang Provincial Communications Department (Grant no. 2017004).

\section{References}

[1] L. Casagrande, "Electro-osmosis in soils," Geotechnique, vol. 1, no. 3, pp. 159-177, 1948.

[2] C.-Y. Ou, S.-C. Chien, and R.-H. Liu, "A Study of the effects of electrode spacing on the cementation region for electro-osmotic chemical treatment," Applied Clay Science, vol. 104, pp. 168-181, 2015.

[3] $\mathrm{H}$. Wu, L. Hu, and Q. Wen, "Electro-osmotic enhancement of bentonite with reactive and inert electrodes," Applied Clay Science, vol. 111, pp. 76-82, 2015.

[4] Y. Shen, Y.-d. Li, W.-j. Huang, H.-d. Xu, and P.-f. Hu, "Vertical drainage capacity of new electrical drainage board on improvement of super soft clayey ground," Journal of Central South University, vol. 22, no. 10, pp. 4027-4034, 2015.

[5] L. Bjerrum, J. Moum, and O. Eide, "Application of electroosmosis to a foundation problem in a norwegian quick clay," Géotechnique, vol. 17, no. 3, pp. 214-235, 1967.

[6] K. Y. Lo, K. S. Ho, and I. I. Inculet, "Field test of electroosmotic strengthening of soft sensitive clay," Canadian Geotechnical Journal, vol. 28, no. 1, pp. 74-83, 1991.

[7] C. J. F. P. Jones, J. Lamont-Black, and S. Glendinning, "Electrokinetic geosynthetics in hydraulic applications," Geotextile and Geomembranes, vol. 29, no. 4, pp. 381-390, 2011.

[8] H.-1. Liu, Y.-1. Cui, Y. Shen, and X.-m. Ding, "A new method of combination of electroosmosis, vacuum and surcharge preloading for soft ground improvement," China Ocean Engineering, vol. 28, no. 4, pp. 511-528, 2014.

[9] C. Y. LiJ. Zhou et al., "Application of vertical layered power technology in electro-osmosis combined with vacuum preloading," in Proceeding of the 11th International Conference on Geosynthetics, Seoul, Korea, September 2018.

[10] H. T. Fu, J. Wang, Y. Q. Cai et al., "Experimental study of combined application of electro-osmosis and low-energy dynamic compaction in soft ground reinforcement," Chinese Journal of Rock Mechanics and Engineering, vol. 34, no. 3, pp. 612-620, 2015.

[11] P. C. Hu, J. Zhou, X. G. Wen et al., "Laboratory model experiment of electro-osmosis combined with loading and pneumatic fracturing," Journal of Zhejiang University (Engineering Science), vol. 49, no. 8, pp. 434-1440, 2015.

[12] Y. F. Zhuang and Z. Wang, "Study on interface electric resistance of electro-osmotic consolidation," Rock and Soil Mechanics, vol. 1, pp. 117-120, 2004.

[13] S. D. Wang, L. H. Zhuang, H. J. Wu et al., "Parameter design of over-wet soil fill treated by electro-osmosis," Chinese Journal of Geotechnical Engineering, vol. 32, no. 2, pp. 211215, 2010.

[14] Y. F. Zhuang, "Theory and design method for electro-osmotic consolidation," Chinese Journal of Geotechnical Engineering, vol. 38, no. S1, pp. 152-155, 2016.

[15] J. Yuan and M. A. Hicks, "Numerical analysis of electroosmosis consolidation: a case study," Géotechnique Letters, vol. 5, no. 3, pp. 147-152, 2015.
[16] J. Yuan and M. A. Hicks, "Numerical evaluation of optimal approaches for electro-osmosis dewatering," Drying Technology, vol. 36, no. 8, pp. 973-989, 2018.

[17] C. C. Chang and M. S. Sheen, "Deduction of three-dimensional electro-osmotic theory," Environmental Geotechnics, vol. 3, no. 1, pp. 47-60, 2016.

[18] L. Hu and $\mathrm{H}$. Wu, "Mathematical model of electro-osmotic consolidation for soft ground improvement," Géotechnique, vol. 64, no. 2, pp. 155-164, 2014.

[19] H. Wu, W. Qi, L. Hu, and Q. Wen, "Electro-osmotic consolidation of soil with variable compressibility, hydraulic conductivity and electro-osmosis conductivity," Computers and Geotechnics, vol. 85, pp. 126-138, 2017.

[20] J. K. Mitchell, "Conduction phenomena: from theory to geotechnical practice," Géotechnique, vol. 41, no. 3, pp. 299-340, 1991. 